\title{
A water soluble electro-catalyst for generating hydrogen based on a cobalt(III) complex supported by 1,10-phenanthroline
}

Qiu-Xia Peng, Ling-Zhi Tang, Shi-Tao Ren, Li-Ping Ye, Yuan-Fu Deng, Shu-Zhong Zhan*

College of Chemistry and Chemical Engineering, South China University of Technology, Guangzhou 510640, China

\section{Abstract}

As we know, coordinatively unsaturated complexes can catalyze hydrogen generation via an unstable hydride intermediate. In this paper, we report an electrocatalyst based on a water soluble coordinatively saturated complex, $\left[(\mathrm{phen})_{2} \mathrm{Co}(\mathrm{CN})_{2}\right] \cdot \mathrm{NO}_{3} \mathbf{1}$ that is formed by the reaction of 1,10-phenanthroline (phen), $\mathrm{Co}\left(\mathrm{NO}_{3}\right)_{2} \cdot 6 \mathrm{H}_{2} \mathrm{O}$ and tetracyanoethylene (TCNE). Its structure has been characterized by physics-chemical and spectroscopic methods. Complex 1 can electrocatalyze hydrogen evolution both from acetic acid and aqueous buffer.

Keywords: Coordinatively saturated cobalt(III) complex; molecular catalyst; proton or water reduction; hydrogen generation

\footnotetext{
* Corresponding author. Fax: +86 2087112053.

E-mail address: shzhzhan@scut.edu.cn (S.-Z.Zhan).
} 


\section{Introduction}

A main aim of coordination chemistry is the design of compounds that exhibit novel properties, such as magnetic coupling and catalysis, etc. We focus our interests on the assembly of new kind molecular catalysts for hydrogen generation via proton and water reduction reactions, as hydrogen can be as a source of clean and renewable fuel [1]. Catalytic proton or water reduction to form $\mathrm{H}_{2}$ has been the subject of present study and much effort has been made to design coordinatively unsaturated complexes supported by tetra- and pentadentate ligands for proton or water reduction [2-4], because catalytic reactions often occur on the metal centers. In nature, hydrogenase enzymes, nickel or iron complexes can efficiently catalyze hydrogen production [5]. However, the difficulty to obtain in sufficient amounts to adapt for commercial applications and instability are limited outside of their native environment $[5,6]$. Therefore, many research groups, including ours, have designed a series of molecular electrocatalysts for dihydrogen production via the reduction of proton or water based on transition metal complexes, for example nickel [7,8], cobalt [9-13], and copper [14-17] complexes. Despite these advances, few electro-catalysts for hydrogen production based on coordinatively saturated complexes are known. In this

paper, we report the synthesis of a six-coordinated cobalt complex $\left[\mathrm{Co}(\text { phen })_{2}(\mathrm{CN})_{2}\right] \cdot \mathrm{NO}_{3}$ 1. This complex can electrocatalyze $\mathrm{H}_{2}$ production both from acetic acid and aqueous buffer.

\section{Experimental}


Synthesis of complex 1

To a solution containing 1,10-phenanthroline monohydrate $(0.396 \mathrm{~g}, 2 \mathrm{mmol})$ and $\mathrm{Co}\left(\mathrm{NO}_{3}\right) \cdot 6 \mathrm{H}_{2} \mathrm{O}(0.291 \mathrm{~g}, 1 \mathrm{mmol})$ in methanol $(20 \mathrm{ml})$, tetracyanoethylene (TCNE) (0.129 $\mathrm{g}, 1 \mathrm{mmol})$ in $\mathrm{CH}_{3} \mathrm{CN}(10 \mathrm{ml})$ was added and the mixture was stirred for $2 \mathrm{~h}$. Red crystals were obtained from the filtrate which was allowed to stand at $25{ }^{\circ} \mathrm{C}$ for several days, collected by filtration, and dried in vacuo $(0.35 \mathrm{~g}, 65 \%$ yield $) .{ }^{1} \mathrm{H}$ NMR $\left(400 \mathrm{MHz}\right.$, acetone- $\left.\mathrm{d}_{6}\right) \delta 9.87(\mathrm{~d}, J=5.2 \mathrm{~Hz}, 2 \mathrm{H}), 9.31(\mathrm{~d}, J=8.3 \mathrm{~Hz}, 2 \mathrm{H}), 8.95(\mathrm{~s}$, 2H), $8.61-8.53(\mathrm{~m}, 4 \mathrm{H}), 8.47(\mathrm{~d}, J=8.8 \mathrm{~Hz}, 2 \mathrm{H}), 7.85(\mathrm{~d}, J=3.7 \mathrm{~Hz}, 4 \mathrm{H})$. The elemental analysis results (Found C, 59.08; H, 3.02; N, 18.47. $\mathrm{C}_{26} \mathrm{H}_{16} \mathrm{~N}_{7} \mathrm{O}_{3}$ Co requires C, 58.55; H, 3.02; N, 18.38) were in agreement with the formula of the sample used for X-ray analysis. IR band $\left(\mathrm{KBr}\right.$ pellet, $\left.\mathrm{cm}^{-1}\right): v=2134(\mathrm{~s}) \quad v(\mathrm{C} \equiv \mathrm{N})$.

\section{Results and discussion}

General characterization

Experimentally, in the presence of TCNE, 1,10-phenanthroline (phen) reacts with $\mathrm{Co}\left(\mathrm{NO}_{3}\right)_{2} \cdot 6 \mathrm{H}_{2} \mathrm{O}$ to afford red crystals of the complex $\left[\mathrm{Co}(\text { phen })_{2}(\mathrm{CN})_{2}\right] \cdot \mathrm{NO}_{3} \mathbf{I}$ in high yield $(65 \%)$, which is soluble in organic solvents and water. From Fig. S1, ${ }^{1} \mathrm{H}$ NMR data of complex 1 are similar to those of phen (Fig. S2), suggesting that no magnetic exchange interaction between cobalt ion and phen [18]. This result is consistent with the magnetic analysis that cobalt ion is at one low spin state $(S=0)$ (a diamagnetic sample). The infrared spectrum of 1 shows one $v(\mathrm{CN})$ stretching at 2134 $\mathrm{cm}^{-1}$ at higher energies than that of the free $\mathrm{CN}^{-}$ion $\left(2080 \mathrm{~cm}^{-1}\right)$, assigning to the cyanide mode in complex 1 (Fig. S3). The electronic spectra of complex 1 and the 
related compounds were recorded in $\mathrm{CH}_{3} \mathrm{CN}$. From Fig. S4, 1 shows one band at 272 $\mathrm{nm}$, which can be attributed to phen to $\mathrm{Co}^{\mathrm{III}}$ charge transfer (CT) transition. As shown in Fig. S5, in the $\mathrm{pH}$ range 3.0 to 12.1 , no new peak appeared, suggesting this complex is stable under these conditions.

According to Fig. 1, complex 1 reveals a six-coordinated cobalt atom in an octahedral surrounding. The cobalt cyano groups show the mutual cis configuration. The Co-N bond lengths fall in the range 1.941(3) to 1.973(3) $\AA$. Note, complex 1 exhibits the same state in solid and liquid. This is in agreement with results from ESI-MS measurement which shows one ion at a mass-to-charge ratio $(\mathrm{m} / \mathrm{z})$ of 471.0776, with the mass and isotope distribution pattern corresponding to that of $\left[(\text { phen })_{2} \operatorname{Co}(\mathrm{CN})_{2}\right]^{+}$(calculated $\mathrm{m} / z$ of 471.3854$)$ (Fig. S6).

\section{Linear scan voltammetry}

To test if this complex can act as an electrocatalyst, first we used linear scan voltammetry (LSV) to investigate its electrochemical behavior. When the electrolyte was removed under Ar atmosphere, followed by addition of $8 \mathrm{~mL}$ of degassed neutral phosphate buffer solution ( $0.25 \mathrm{M}, \mathrm{pH} 7.0)$, then a linear sweep scan was performed, an intense cathodic current could be observed (Fig. S7). As shown in Fig. 2, the potentials for reduction of $\mathbf{1}$ are the same as that of the back-ground (ca. $-1.55 \mathrm{~V}$ versus $\mathrm{Ag} / \mathrm{AgCl}$ ), indicating that no proton is lost during the initial reduction. According to Fig. S8, the peak current increases continually with increasing complex 1 concentration from 0.0 to $8.603 \mu \mathrm{M}$, and no turning point is found, demonstrating 
that 1 undergoes redox cycling during the electrochemical experiments. From Fig. S9, The catalytic current increases significantly with decrease of $\mathrm{pH}$ from 7.0 to 3.0, suggesting that there is a protonation step in the catalytic reaction.

Cyclic voltammetry

We then investigated the electrochemical behavior of complex $\mathbf{1}$ by cyclic voltammetry. From Fig. 3a, 1 shows three reversible redox peaks at $-0.59,-1.525$ and $-1.735 \mathrm{~V}$ versus $\mathrm{Ag} / \mathrm{AgNO}_{3}$, which can be assigned to the couples of $\mathrm{Co}^{\mathrm{III} / \mathrm{II}}, \mathrm{Co}^{\mathrm{II} / \mathrm{I}}$ and $\mathrm{Co}^{\mathrm{I} / 0}$, respectively. As observed in Fig. S10, the current response of the redox event at $-1.59 \mathrm{~V}$ versus $\mathrm{Ag} / \mathrm{AgNO}_{3}$ shows linear dependence on the square root of the scan rate, which is an indicative of a diffusion-controlled process.

Catalytic hydrogen evolution from acetic acid in $\mathrm{CH}_{3} \mathrm{CN}$

To test the catalytic activity of this complex, acetic acid was employed as the proton resource and electrochemical measurements of complex $\mathbf{1}$ were performed with varying concentrations of acetic acid. From Fig. $3 \mathrm{~b}$ it can be seen that the catalytic current near -1.76 and $-1.59 \mathrm{~V}$ versus $\mathrm{Ag} / \mathrm{AgNO}_{3}$ increased markedly with the sequential increments of acid concentration (from 0.00 to $1.333 \mathrm{mM}$ ). This rise in current can be attributed to the catalytic generation of $\mathrm{H}_{2}$ from acetic acid [19]. The result indicates that hydrogen evolution electrocatalyzed by complex $\mathbf{1}$ needs the reduction potentials of $\mathrm{Co}(\mathrm{II})$ to $\mathrm{Co}(\mathrm{I})$ and $\mathrm{Co}(\mathrm{I})$ to $\mathrm{Co}(0)$. Note, with the acetic acid concentration increased from 0.00 to $1.333 \mathrm{mM}$ (Fig. 3b), the reduction potentials near -1.76 and $-1.59 \mathrm{~V}$ versus $\mathrm{Ag} / \mathrm{AgNO}_{3}$ remain almost constant, but the peak 
strengths increased markedly. The onset of the catalytic wave also remains almost constant at $-1.42 \mathrm{~V}$ versus $\mathrm{Ag} / \mathrm{AgNO}_{3}$.

To test that the product of this reaction was hydrogen gas, CPE of a $3.44 \mu \mathrm{M}$ complex 1 containing $2.0 \mathrm{mM}$ acetic acid was conducted in a double-compartment cell using a glassy carbon plate electrode. Fig. S11 shows the charge of bulk electrolysis from complex $\mathbf{1}$ in presence of acetic acid, the charge significantly increased when the applied potential was set to more negative. In the absence of complex 1, CPE experiment gave a charge of $3 \mathrm{mC}$ used in $2 \mathrm{~min}$ under $1.40 \mathrm{~V}$ versus $\mathrm{Ag} / \mathrm{AgNO}_{3}$ (Fig. S11a). Under the same conditions, the addition of complex 1 led to increase a marked increase on the accumulation of charge with more negative potential. When the applied potential was $-1.40 \mathrm{~V}$ versus $\mathrm{Ag} / \mathrm{AgNO}_{3}$, the maximum charge reached $122 \mathrm{mC}$ during 2 min of electrolysis (Fig. S11b), accompanying by a gas appeared, which was confirmed to be $\mathrm{H}_{2}$ by $\mathrm{GC}$ analysis. The evolved $\mathrm{H}_{2}$ was analyzed by gas chromatography, Fig. S12, which gave $\sim 0.049 \mathrm{~mL}$ of $\mathrm{H}_{2}$ over an electrolysis period of $2 \mathrm{~h}$. The result shows this complex does serve an effective hydrogen production under such conditions. Based on Equations (1) [20] and (2) [21], complex 1 gives a TOF of 0.0154 moles of hydrogen per mole of catalyst per second at an OP of $891.6 \mathrm{mV}$ (Eq. 2).

$$
\mathrm{TOF}=\Delta C /\left(\mathrm{F}^{*} n_{1} * n_{2} * t\right)
$$

Overpotential $=$ Applied potential $-\mathrm{E}^{\odot} \mathrm{HA}$

$$
=\text { Applied potential }-\left(\mathrm{E}^{\odot}{ }_{\mathrm{H}}^{+}-(2.303 R T / F) \mathrm{p} K_{a \mathrm{HA}}\right)
$$

Where, $\mathrm{F}$ is Faraday's constant, $n_{1}$ is the number of moles of electrons required to 
generate one mole of $\mathrm{H}_{2}, n_{2}$ is the number of moles of catalyst in solution, and $\mathrm{t}$ is the duration of electrolysis; $\Delta C$ is the charge from the catalyst solution minus the charge from solution without catalyst.

Catalytic hydrogen evolution from aqueous buffer

After that, we explored the electrochemical properties in aqueous media. As shown in Fig. S13, in the presence of complex 1, an irreversible wave is observed at $-1.86 \mathrm{~V}$ versus $\mathrm{Ag} / \mathrm{AgCl}$ and the peak current strength increases with increasing concentrations of complex 1 from 0.00 to $0.351 \mu \mathrm{M}$. To further probe this reduction process, we investigated the $\mathrm{pH}$ dependence on the cathodic peak potential. From Fig. $\mathrm{S} 14$, the peak current strength increases significantly under lower $\mathrm{pH}$ values, which is consist with a catalytic process [22], indicating $\mathbf{1}$ indeed can catalyze hydrogen generation via water reduction reactions.

To further obtain the evidence for the activity in aqueous media, the bulk electrolysis of a $3.44 \mu \mathrm{M}$ complex 1 was conducted in a natural buffer under variable applied potentials. According to Fig. 4a, when the applied potential is $-1.45 \mathrm{~V}$ versus $\mathrm{Ag} / \mathrm{AgCl}$, in the absence of complex $\mathbf{1}$, the maximum charge is only $24 \mathrm{mC}$ during $2 \mathrm{~min}$ of electrolysis. Under the same conditions, the CPE experiment provided $888 \mathrm{mC}$ of charge with addition of complex 1 (Fig. 4b), accompanied by the appearance of gas bubbles which was confirmed to be $\mathrm{H}_{2}$ by $\mathrm{GC}$ analysis. From Fig. $\mathrm{S} 15, \sim 5.12 \mathrm{~mL}$ of $\mathrm{H}_{2}$ was obtained over an electrolysis period of $1 \mathrm{~h}$. According to Equations (1) and (3) [22], we also calculated the TOF for the catalyst as reaching a maximum of 0.25 
moles of hydrogen per mole of catalyst per second at an OP of $837.6 \mathrm{mV}$ (Eq. S2). Remarkably, there is about 15 times (from 0.0154 to 0.25 ) increase in the rate of $\mathrm{H}_{2}$ evolution, because more protons can be offered from aqueous buffer than that from $\mathrm{CH}_{3} \mathrm{CN}$ with $2.0 \mathrm{mM}$ acetic acid.

Overpotential $=$ Applied potential $-\mathrm{E}(\mathrm{pH})=$ Applied potential- $(-0.059 \mathrm{pH})$

From Fig. S16, the TOF of 664 moles $\mathrm{h}^{-1}$ at an OP of $688 \mathrm{mV}$ produced by complex $\mathbf{1}$ is higher than some known molecular cobalt catalysts for electrochemical hydrogen production from neutral water. For instance, a cobalt(II) complex with picolinic acid ions that exhibits a TOF of 350.6 moles $^{-1}$ at an OP of $688 \mathrm{mV}$ [24], a cobalt complex supported by macrocyclic ligand displaying a turnover number of 0.4 moles of $\mathrm{H}_{2}$ per mole of catalyst per hour at an $\mathrm{OP}$ of $390 \mathrm{mV}$ [25] and a cobalt(II) complex with $\mathrm{N}, \mathrm{N}$ '-bis(2'-pyridinecarboxamide)-1,2-benzene, $\mathrm{Co}\left(\mathrm{bpbH}_{2}\right) \mathrm{Cl}_{2}$ (376 moles $\mathrm{h}^{-1}$ at an OP of $688 \mathrm{mV}$ ) [26].

Investigation of the stability and durability of complex $\mathbf{1}$

In order to test whether 1 retains activity for water reduction for a long time, a 72 h CPE experiment was performed in a natural buffer solution with $4.0 \mu \mathrm{M}$ complex 1 under $-1.45 \mathrm{~V}$ versus $\mathrm{Ag} / \mathrm{AgCl}$. According to Fig. S17a, a total of $1165 \mathrm{C}$ was passed during a 72 h electrolysis. And compound 1 gives a charge build-up over time, with no substantial loss in activity over the course of $72 \mathrm{~h}$. After a $72 \mathrm{~h}$ electrolysis period, $\mathrm{pH}$ increases by 4.5 units (from 7.0 to 11.5 ), consistent with accumulation of $\mathrm{OH}^{-}$by 
water reduction, $2 \mathrm{H}_{2} \mathrm{O}+2 \mathrm{e} \rightarrow \mathrm{H}_{2}+2 \mathrm{OH}^{-}$. From Fig. $\mathrm{S} 17 \mathrm{~b}$, the catalytic current remains almost constant for at least $72 \mathrm{~h}$, indicating this catalyst is stable under these conditions.

To prove complex $\mathbf{1}$ acts as a homogeneous electrocatalyst, we checked dependence of the catalytic current on concentration of complex 1. According to Fig. S13, the observation of the catalytic current being dependent on concentration of complex $\mathbf{1}$ could indicate $\mathbf{1}$ is a homogeneous catalyst. And the following pieces of evidence also suggest that complex $\mathbf{1}$ is a homogeneous electrocatalyst: a) The catalytic current did not increase after several cycle CV scans (Fig. S18) [27]. b) No precipitation was found in the solution and the color of the solution did not change during cyclic voltammetry or bulk electrolysis. c) Under the same conditions, no precipitates were formed on a blank glassy carbon electrode after $3 \mathrm{~h}$ of electrolysis, as determined by EDS measurement (Fig. S19).

\section{Conclusion}

Successfully prepared a new type of electro-catalyst based on a coordinately saturated cobalt(III) complex. Electrochemical studies show that this complex can electrocatalyze hydrogen evolution both from acetic acid, with a TOF of 0.0154 moles of $\mathrm{H}_{2}$ per mole of catalyst per second at an $\mathrm{OP}$ of $891.6 \mathrm{mV}$ (in $\mathrm{CH}_{3} \mathrm{CN}$ ), and from a neutral aqueous buffer ( $\mathrm{pH} 7.0$ ) with a TOF of 0.25 moles of $\mathrm{H}_{2}$ per mole of catalyst per second at an OP of $837.6 \mathrm{mV}$. Ongoing efforts are focused on the study of the catalytic mechanism for proton or water reduction by coordinately saturated 
complexes.

\section{Acknowledgements}

This work was supported by the National Science Foundation of China (No. 20971045, 21271073) and the Fundamental Research Funds for the Central Universities (2015ZZ046).

\section{References}

[1] J. A. Turner, Science 305 (2004) 972-974.

[2] J. R. McKone, S. C. Marinescu, B. S. Brunschwig, J. R. Winkler, H. B. Gray, Chem. Sci. 5 (2014) 865-878.

[3] A. Lewandowska-Andralojc, T. Baine, X. Zhao, J. T. Muckerman, E. Fujita, D. E. Polyansk, Inorg. Chem. 54 (2015) 4310-4321.

[4] D. Z. Zee, T. Chantarojsiri, J. R. Long, C. J. Chan, Acc. Chem. Res. 48 (2015) $2027-2036$.

[5] J. C. Fontecilla-Camps, A. Volbeda, C. Cavazza, Y. Nicolet, Chem. Rev. 107 (2007) 4273-4303.

[6] C. J. Pickett, C. Tard, Chem. Rev. 109 (2009) 2245-2274.

[7] M. L. Helm, M. P. Stewart, R. M. Bullock, M. R. DuBois, D. L. DuBois, Science 333 (2011) 863-866.

[8] J. P. Cao, T. Fang, L. Z. Fu, L. L. Zhou, S. Z. Zhan, Int. J. Hydrogen Energy 39 (2014) 10980-10986. 
[9] Y. Sun, J. P. Bigi, N. A. Piro, M. L. Tang, J. R. Long, C. J. Chang, J. Am. Chem. Soc. 133 (2011) 9212-9215

[10] L. Z. Fu, L. L. Zhou, L. Z. Tang, Y. X. Zhang, S. Z. Zhan, J. Power Sources 280 (2015) 453-458.

[11] B. D. Stubbert, J. C. Peters, H. B. Gray, J. Am. Chem. Soc. 133 (2011) 18070-18073.

[12] W. M. Singh, T. Baine, S. Kudo, S. Tian, X. A. N. Ma, H. Zhou, N. J. DeYonker,

T. C. Pham, J. C. Bollinger, D. L. Baker, B. Yan, C. E. Webster, X. Zhao, Angew. Chem. Int. Ed. 51 (2012) 5941-5944.

[13] L. Tong, R. Zong, R. P. Thummel, J. Am. Chem. Soc. 136 (2014) 4881-4884.

[14] T. Fang, L. Z. Fu, L. L. Zhou, S. Z. Zhan, Electrochimica Acta 161 (2015) 388-394.

[15] J. P. Cao, T. Fang, L. Z. Fu, L. L. Zhou, S. Z. Zhan, Int. J Hydrogen Energy 39 (2014) 13972-13978.

[16] L. L. Zhou, T. Fang, J. P. Cao, Z. Zhu, X. Su, S. Z. Zhan, J. Power Sources 273 (2015) 298-304.

[17] P. Zhang, M. Wang, Y. Yang, T. Yao, L. Sun, Angew. Chem. Int. Ed. 53 (2014) 13803-13807.

[18] C.-H. Cho, T.-Y. Chien, J.-H. Chen, S.-S. Wang, J.-Y. Tung, Dalton Trans. 39 (2010) 2609-2614.

[19] H. I. Karunadasa, C. J. Chang, J. R. Long, Nature 464 (2010) 1329-1333. 
[20] J. P. Cao, L. L. Zhou, L. Z. Fu, J. X. Zhao, H. X. Lu, S. Z. Zhan, Cata. Commun. 57 (2014) 1-4.

[21] G. A. N. Felton, R. S. Glass, D. L. Lichtenberger, D. H. Evans, Inorg. Chem. 45 (2016) 9181-9184.

[22] R. S. Nichloson, I. Shain, Anal. Chem. 36 (1964) 706-723.

[23] Y. Sun, J. P. Bigi, N. A. Piro, M. L. Tang, J. R. Long, C. J. Chang, J. Am. Chem. Soc. 133 (2011) 9212-9215.

[24] L. Z. Fu, L. Z. Tang, Y. X. Zhang, Q. N. Liang, C. Fang, S. Z. Zhan, Int. J. Hydrogen Energy 41 (2016) 249-254.

[25] P. V. Bernhardt, L. A. Jones, Inorg. Chem. 38 (1999) 5086-5090.

[26] Z. Q. Wang, L. Z. Tang, Y. X. Zhang, S. Z. Zhan, J. S. Ye, J. Power Sources 287 (2015) 50-57.

[27] W. T. Lee, S. B. Munoz III, D. A. Dickie, J. M. Smith, Angew Chem. Int. Ed. 53 (2014) 9856-9859. 


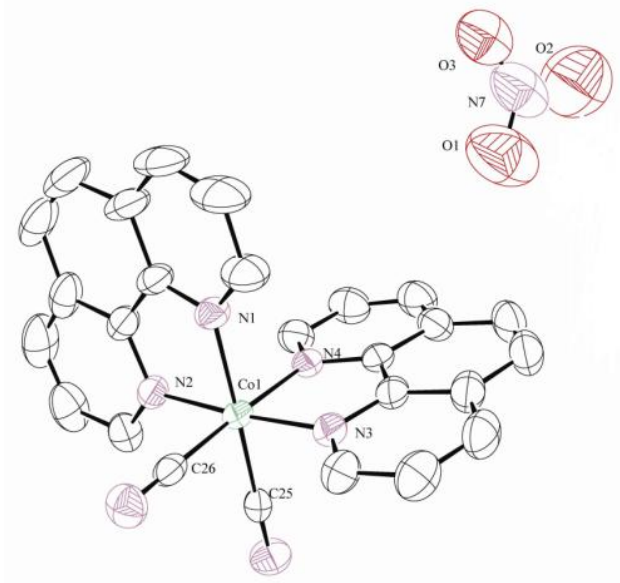

Fig. 1. ORTEP drawing of complex 1 with thermal ellipsoids on the 50\% probability level (hydrogen atoms are not shown). 


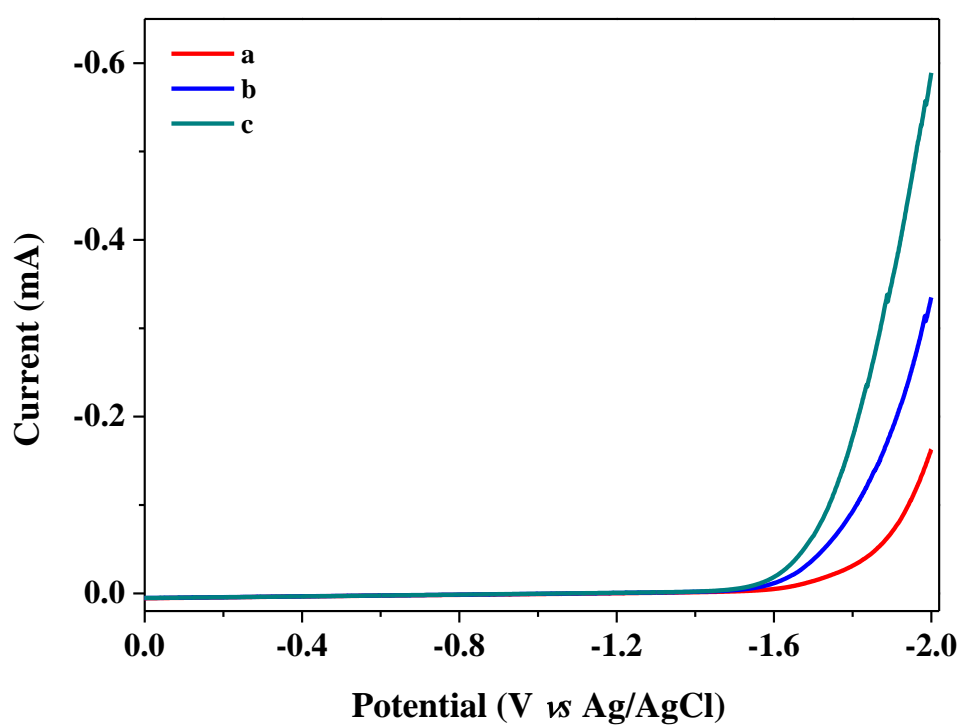

Fig. 2. Linear sweep voltammograms (LSVs) of a neutral buffer ( $\mathrm{pH}$ 7.0) containing $0.80 \mathrm{M}$ complex 1 with different kinds of glassy carbon electrodes, scan rate: 100 $\mathrm{mV} / \mathrm{s}$. (a) Unmodified electrode. (b) Modified electrode exposed to air prior to LSV. (c) Modified electrode rinsed with $\mathrm{CH}_{3} \mathrm{CN}$ and dried under $\mathrm{Ar}$ atmosphere. 

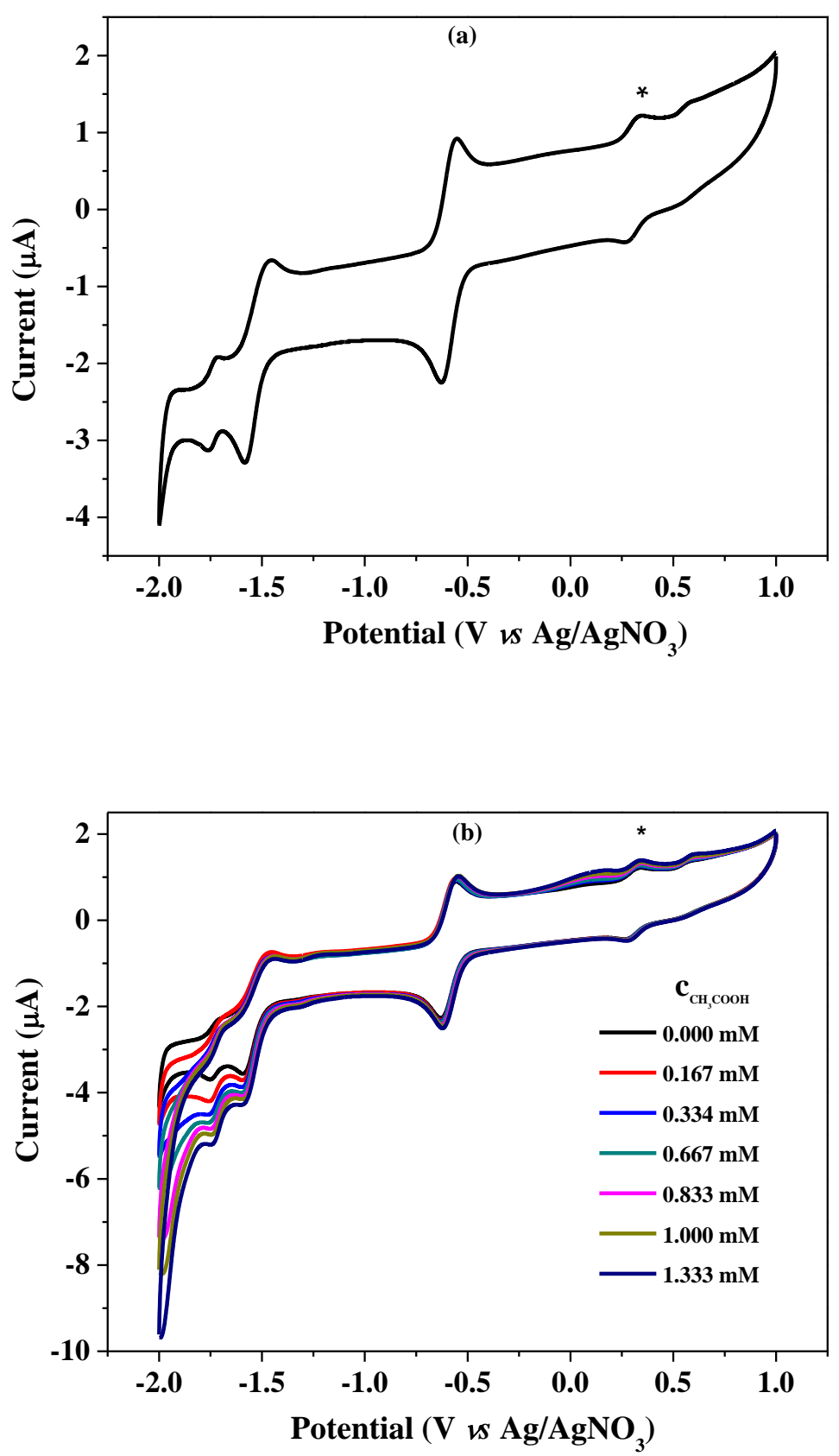

Fig. 3. (a) Cyclic voltammogram (CV) of $0.8 \mathrm{mM}$ complex 1 in $\mathrm{CH}_{3} \mathrm{CN}$. (b) $\mathrm{CVs}$ of a $0.8 \mathrm{mM}$ solution of complex $\mathbf{1}$, with varying concentrations of acetic acid in $\mathrm{CH}_{3} \mathrm{CN}$. Conditions: $0.10 \mathrm{M}\left[\mathrm{n}-\mathrm{Bu}_{4} \mathrm{~N}\right] \mathrm{ClO}_{4}$ as supporting electrolyte, scan rate: $100 \mathrm{mV} / \mathrm{s}$, glassy carbon working electrode ( $1 \mathrm{~mm}$ diameter), $\mathrm{Pt}$ counter electrode, $\mathrm{Ag} / \mathrm{AgNO}_{3}$ reference electrode. 

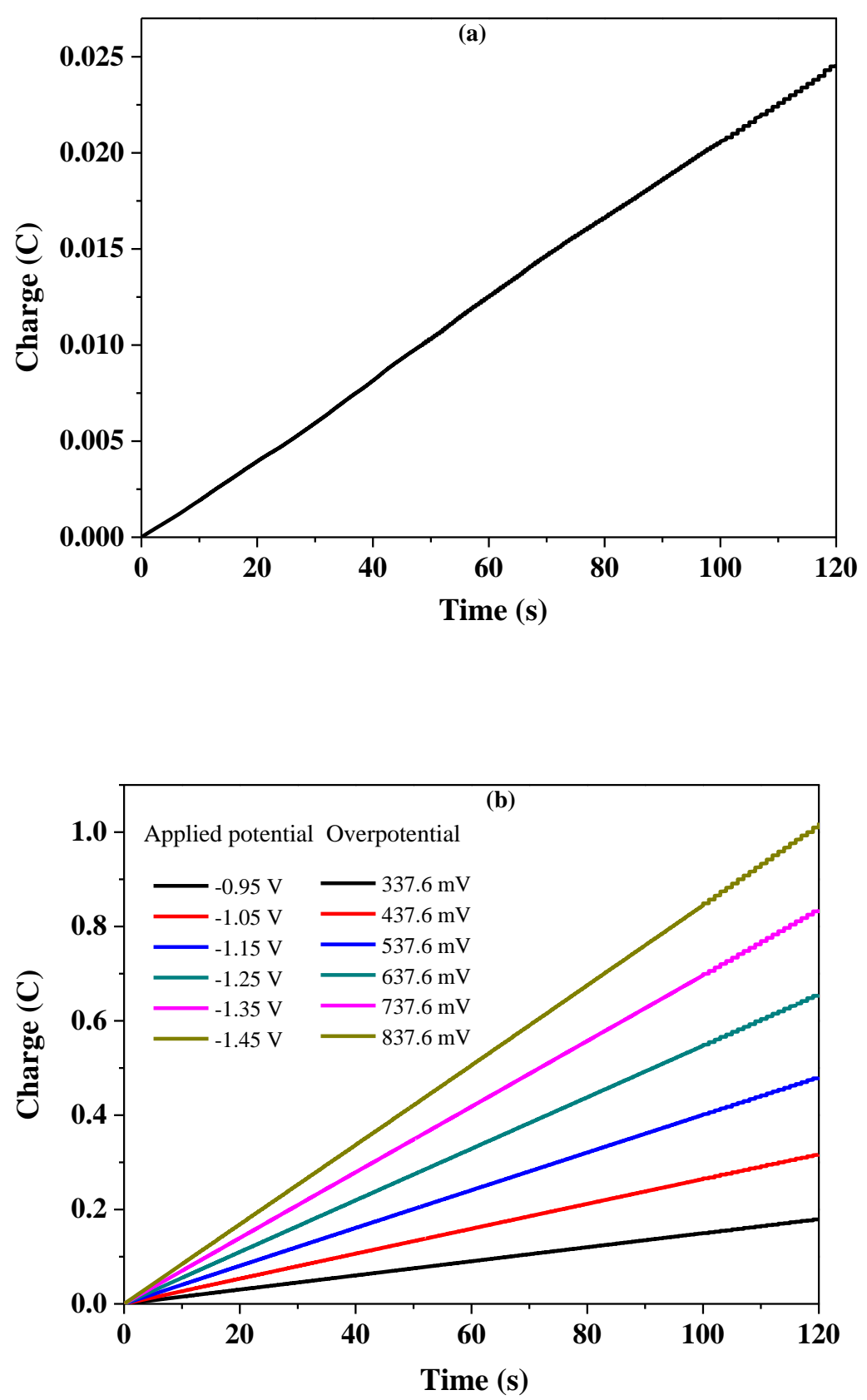

Fig. 4. (a) Charge buildup versus time from electrolysis of a $0.25 \mathrm{M}$ buffer (pH 7.0) under -1.45 V versus $\mathrm{Ag} / \mathrm{AgCl}$. (b) Charge buildup versus time from electrolysis of a $4.0 \mu \mathrm{M}$ complex 1 in a $0.25 \mathrm{M}$ buffer $(\mathrm{pH}$ 7.0) under a series of applied potentials. All data have been deducted blank. 


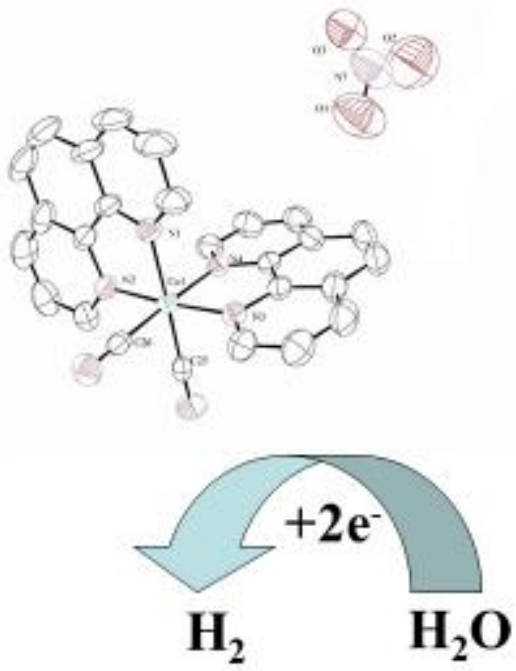

